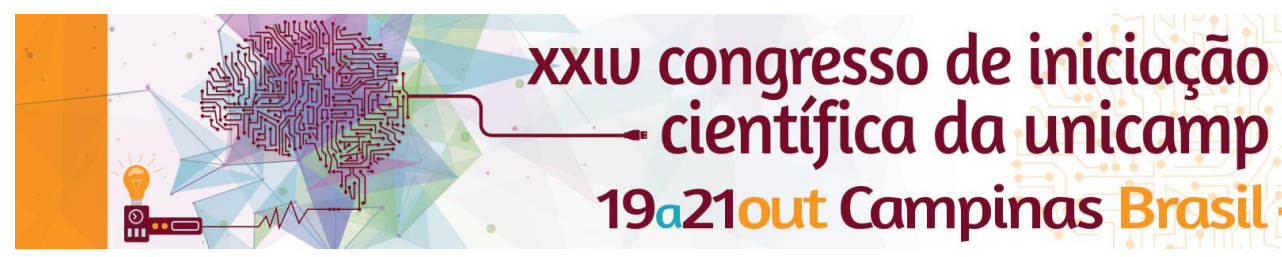

\title{
Influência dos neutrinos no processo de formação de inomogeneidades e estruturas no universo
}

\section{João V. C. Rocha*}

\section{Resumo}

Para entender como surgiram as inomogeneidades e anisotropias, deve-se analisar as pequenas flutuações que ocorreram no espaço no Universo primordial. No início dos tempos, estipula-se que tenha ocorrido um fenômeno denominado inflação, no qual houve expansão extremamente rápida do espaço. Nessa ocasião teriam surgido as primeiras irregularidades na distribuição de densidades dos componentes cosmológicos (fótons, elétrons, matéria escura, etc.). Com o passar do tempo, a matéria passou a se concentrar em algumas regiões do universo e, através da gravitação, cada vez mais e mais matéria foi se aglomerando, até formar as grandes estruturas que observamos atualmente. Para tanto, um dos agentes fundamentais nesse processo é o neutrino. Em virtude de sua abundância (perdendo somente para o fóton), a atração gravitacional e sua pressão de radiação foram fundamentais na expansão das irregularidades. Por isso, a intenção é estudar sua participação no processo cosmológico de formação de estruturas.

\section{Palavras-chave:}

Cosmologia, Inomogeneidades, Neutrinos.

\section{Introdução}

A evolução das inomogeneidades é regida por um sistema de equações diferenciais. Para resolvê-las, precisamos lançar mão das condições iniciais do universo, que é basicamente estudar o período inflacionário.

Além disso, deve-se conhecer as propriedades dos neutrinos, para aplicar as equações sobre o mesmo. Nos momentos iniciais do Big Bang, ele possuía caráter relativístico, contribuindo com a evolução das perturbações por meio da pressão de radiação. Contudo, na medida em que a temperatura diminuía, a energia cinética dos neutrinos também. Ou seja, o caráter relativístico passa a dar lugar ao comportamento de matéria.

O resultado é expresso em termos do espectro de potência, o qual é relacionado com as inomogeneidades. Essa, por sua vez, é caracterizada pela densidade média de galáxias.

\section{Resultados e Discussão}

É necessário resolver o sistema de equações diferenciais ordinárias abaixo:

$$
\begin{aligned}
& \dot{\Theta}_{0}+k \Theta_{1}=-\dot{\Phi} \\
& \dot{\Theta}_{1}-\frac{k}{3} \Theta_{0}=\frac{-k}{3} \Phi \\
& \dot{\delta}+i k v=-3 \dot{\Phi} \\
& \dot{v}+\frac{\dot{a}}{a} v=i k \Phi \\
& -k^{2} \Phi+3 \frac{\dot{a}}{a}\left(\dot{\Phi}+\frac{\dot{a}}{a} \Phi\right)=4 \pi G a^{2}\left[\rho_{d m} \delta+4 \rho_{r} \Theta_{0}\right]
\end{aligned}
$$

A solução deve ser obtida numericamente para as incógnitas $\Theta_{0}, \Theta_{1}, \Phi, \delta$ e $v$. O espectro de potência em função de $\mathrm{k}$ é mostrado no gráfico da figura 1:

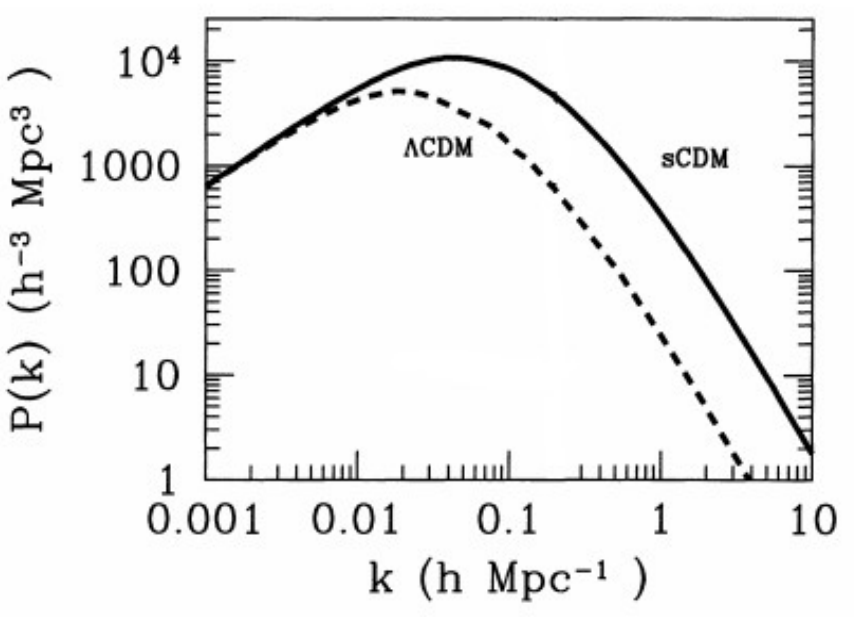

Figura $1^{[1]}$. Ilustração adaptada, demostrando o resultado esperado do gráfico $\log x \log$ do espectro de potência em função do número de onda $\mathrm{k}$. A curva tracejada denota o modelo incluindo a constante cosmológica $(\Lambda C D M)$ e a contínua sem a constante cosmológica (sCDM).

\section{Conclusão}

Os resultados obtidos utilizaram a aproximação que o neutrino é uma partícula sem massa (pois é uma partícula extremamente leve) e sem colisão (de difícil interação). Para modelos mais precisos, é necessário incluir massa e colisão. O modelo aproximado apresenta bons resultados se considerarmos os primórdios do universo, depois do primeiro minuto de existência.

\section{Agradecimentos}

Agradeço meu orientador, Pedro Cunha de Holanda, por todo o apoio para que fosse possível realizar esse projeto, e ao CNPq pela bolsa oferecida. 